\title{
IT-competence as a Professional Feature of Modern Teachers
}

\author{
Guzelia Ahkiyamova \\ Naberezhnye Chelny state \\ pedagogical University, \\ Naberezhnye Chelny state \\ pedagogical University, \\ Naberezhnye Chelny, Russia \\ E-mail: aaarrii@yandex.ru
}

\author{
Alfiya Hasanova \\ Naberezhnye Chelny state \\ pedagogical University, \\ Naberezhnye Chelny state \\ pedagogical University, \\ Naberezhnye Chelny, Russia \\ E-mail: a.khasanova@mail.ru
}

\begin{abstract}
In this article authors prove the relevance of using information technologies to teaching as a whole, and to teaching Life Safety as a curriculum subject in particular. In the process of education, upbringing and development of the modern generation in the information environment, it is necessary to transform the education system, i.e. to form and develop IT-competence of teachers, which is the main task at all levels of the state system of teacher education.
\end{abstract}

Keywords - competence, information technology, educational process, educational environment.

\section{INTRODUCTION}

The professionalism of the teacher is based on the inseparability of knowledge and skills corresponding to the level of development of modern science and technology, i.e. their product - interactive technologies.

The IT culture of the Life Safety teacher means not only the use of modern sources of information and communication tools, the processing of professionally relevant information, but also the opportunity to present the results of their pedagogical work at the highest aesthetic level, using interactive technologies of the 21 st century [1].

At the end of the 20th century, mankind is faced with the problems of integrating the efforts of every nation in the struggle for its survival, preservation of life on the Earth, protection of the natural environment, and elimination of the consequences of emergency situations of any kind.

The "Basics of Life Safety" subject was recommended for study in educational organizations in 1991. The rationale for introducing this course into the educational process of an educational organization can be the provision that the school age is the most favorable for the formation of a person's sense of personal and collective security. It is at this age when it is easy to motivate children and adolescents to follow norms and rules of safe behavior at home, in the street, at school and in nature, which will be the basis for independent adoption of a safe lifestyle in society, the team, the family and the environment [9].

The subject of BLS, although introduced relatively recently, has recommended itself as one of the most important elements of the general educational process. In many regions of Russia, it has received recognition of the pedagogical community, becoming at the same time an exciting and favourite discipline for the students. Today we can confidently say that the course of the BLS has overcome many difficulties and firmly entered the school life [2].

\section{RESULTS AND DISCUSSION}

Of course, realization should be done according to the principle of "simple to complex", ensure that the material corresponds to the age opportunities of students, follow a continuous, but gradual construction of content. It is necessary to nurture optimistic and above all an active attitude to life in students. Ecology considers various types of pollution and harmful effects on humans. Some of them, for example, the impact of electromagnetic radiation affect us constantly, and the reduction of these impacts depends on our knowledge and the ability to behave. In order to raise the level of learning of the BLS in schools and the successful formation of a patriotic outlook in the younger generation, the problem of further improving the existing system of training facilities, taking into account the general trends in the development of educational equipment in our country and abroad, becomes especially important. Social progress is putting its demands on the means of education, and one of the most important trends is the further improvement of the quality of textbooks and their effective use in the educational process. Another trend is related to scientific and technological progress, the emergence of modern technology, new materials, the latest multimedia and telecommunication technologies and helps to improve learning tools.

Consequently, the competence of the Life Safety teacher in the field of interactive technologies consists of:

- general ideas about their didactic potential;

- understanding of the unified information space of educational organizations, computer networks and possibility of their use in the educational process;

- general ideas about ESM and directions of the market of electronic editions in the general education sector;

- possession of the methodology for introducing digital educational resources into the teaching and upbringing process;

- application of the methods of creating an individual information space, the methods of executing file actions, the formation of an information and educational environment as a file system; 
- preparation of didactic materials, presentations in accordance with the subject area and working documents using office technology;

- possession of the basic services and technologies of the Internet in the context of their application in the educational environment of the teacher;

- representations about the technology and resources of distance care of the educational process and the possibility of their inclusion in their pedagogical activities;

- Possession of the technological basis for the creation of a site for the support of educational activities [4].

There is an extremely wide range of professional tasks, which the Life Safety teacher can solve at a higher professional level, if they own the newest interactive technologies (IT) [1].

ITs enable the teacher to expand the range of sources of educational information easily by providing all students with educational material in electronic form, opening access to it, posting, for example, on their website in advance. In addition, they can give a number of links to available sources of materials in the network that would be useful to students. The teacher can in this case not spend the study time on the theoretical part of the information. The lesson can be devoted to the comments, discussion of the educational information, with which they independently familiarized in advance and prepared for the discussion of the problems in question [6].

The peculiarity of the application of material in the electronic format involves the students in the joint "stay" of educational, cognitive and emotional situations on the basis of their own positions. In the process of such training, it becomes common to find two equal centers: a teacher and a student contacting on the basis of mutual respect [7]. For traditional learning, on the contrary, it is inherent in the assimilation of knowledge by the majority of students, where the teacher acts as the only source of information, the truth of which is not to be doubted. This often leads to a formalistic assimilation of knowledge and does not give a good developmental result.

The reference to electronic information resources allows to solve the following problems [6]:

- use graphic, video, animation and software support in the preparation of elements used in electronic educational resources;

- increase the number and variety of sources of educational information available to students;

- reduce the time spent on performing routine operations;

- to solve search creative tasks, in the process of which new knowledge is formed;

- strengthen the role of independent work of students, in the process of which the necessary skills and creative approach to problem solving are more dynamically formed;

- increase the efficiency and objectivity of monitoring the results of student learning;

- organize training on individual curricula.
Continuous work with a different form of presentation of the material makes it possible to increase the cognitive activity of students, to form an additional motivation for learning, to individualize learning. A well-considered scenario for submitting educational material in text, graphic, and in particular video and audio formats allows the teacher to direct the process of perception of students directly, to be constantly and invisibly next to the student, directing their attention to the most important, essential aspects of the phenomenon being studied or the particular features of any mode of action, for example, in natural disasters.

Thus, for the effective use of information and communication technologies in the teaching process, the BLS teacher must be able to [3]:

- $\quad$ systematize, structure, optimize the educational information and present it in a form convenient for mastering;

- $\quad$ solve the tasks of searching, processing and presenting information in electronic form;

- use information technologies in the organization of instruction in the classroom and in extra-curricular educational activities expediently;

- choose the software tools corresponding to the type of information and specific tasks;

- dispense with templates and offer their original solutions for the presentation of educational material, to withstand its aesthetic side;

- $\quad$ use the capabilities of information networks (local school and Internet);

- $\quad$ spend minimal time for mastering a new program;

- minimize the time spent on solving problems of searching, processing and presenting various information with the possibility of using reference systems [7].

Numerous information sources are not always a guarantee of success in mastering a particular academic discipline. It is important to create such conditions under which the information presented would be relevant and necessary for solving practical problems. New information technologies can be effectively used at all training sessions.

To date, testing as a form of control and training is a necessary link in the learning process. Computer testing allows to save time and effort of the teacher in preparing, conducting and checking the results of students' knowledge control, and to offer students test tasks in a variety of dynamic forms with prompt output of the result, in the objectivity of which there is no reason to doubt [5].

Creative project, organized in the course of educational activity, will allow to combine the material review and to consolidate its practical application. It gives an opportunity to develop an emotional-value attitude to knowledge, creative thinking and the student's imagination, which is especially important for further educational and professional activities. 
The teacher implementing new information educational technologies should have a higher level of preparation in order to:

- create high-quality teaching materials, which the students could use independently;

- improve the system of activities and techniques for constant monitoring of students' fulfillment of the curriculum, which includes the formation of a sequence of tasks that the student must solve within the specified time frame;

- use the existing means of the educational information environment of the educational institution easily, including the means for developing electronic demos of teaching materials.

Lessons with the use of IT are based on the following general didactic principles of teaching: the principle of consciousness and activity of students in learning, the principle of scientific approach, he principle of linking learning with practice, the principle of consistency; principle of accessibility, the principle of visibility [4].

The lesson, as a direct tool for implementing the basic ideas of information and communication technologies, requires the most careful development. Lessons are the litmus test that shows the effectiveness of a particular development. They are at the same time the end result, and the final stage of design, implementation of ideas, laid down by developers of certain technologies [8].

Designing of such lessons requires even more thorough preparation than usual. When designing the future multimedia lesson, the teacher should consider the sequence of technological operations, the forms and methods of submitting information to the big screen. One should immediately think about how the teacher will manage the educational process, how the pedagogical communication in the lesson will be provided, constant feedback from the students, developing the learning effect.

Multimedia is a lesson that uses a multi-media representation of information with the help of hardware, primarily a computer. In numerous articles devoted to this topic, the expression "a lesson with multimedia support" is often found. It is quite obvious that this is the lesson where multimedia is used to enhance the learning effect. In this lesson, the teacher remains one of the main participants in the educational process, often the main source of information, and multimedia technologies are used to enhance the visibility, to connect several channels of information at the same time, for a more accessible explanation of new complex material [6].

It is quite clear that the degree and time of the multimedia support of the lesson can be different: from a few minutes to a full cycle. However, the multimedia lesson can also be used as a "mini-technology", that is, as a development prepared by one or another author with the specified learning goals and objectives, oriented to well-defined learning outcomes. Such a lesson has a sufficient set of information component, didactic toolkit. The role of the teacher changes significantly during the lesson, who is, first of all, the organizer, the coordinator of students' cognitive activity in this case [5].
When designing the future multimedia lesson, teachers should reflect on what goals they pursue, what role this lesson plays in the system of lessons on the topic or the entire training course. What the multimedia lesson is for:

- $\quad$ studying new material, presenting new information;

- material review, training of educational skills;

- $\quad$ practical application of acquired knowledge, skills;

- generalization, systematization of knowledge [9].

The teacher should immediately determine whether to use it for strengthening the teaching and nurturing effect of the lesson, or it will simply be a tribute to the newfangled hobbies. Based on this, the teacher selects the necessary forms and methods of conducting a lesson, educational technologies, teaching techniques.

A multimedia lesson can achieve maximum learning effect if it appears as a meaningful integral product, rather than an occasional set of slides. A certain list of oral, visual, textual information turns the slide into an educational episode. The teacher should strive to turn each of the episodes into an independent didactic unit. Pedagogical directories define the didactic unit as a logically independent part of the educational material, according to its volume and structure, corresponding to such content components as concept, theory, law, phenomenon, fact, object [11].

Thus, preparing a training episode and treating it as a didactic unit, the Life Safety teacher must clearly understand what training tasks he pursues with this episode, by what means he will achieve their implementation [7].

One of the obvious advantages of a multimedia lesson is the strengthening of visualization. The well-known phrase of K.D. Ushinsky goes: "Children's nature clearly requires visual aids. Teach a child some five words not known to him, and he will be in long pains remembering them; but associate pictures with twenty unfamiliar words - and the child will learn them on the fly. You explain to the child a very simple idea, and he does not understand you; you explain to the same child a complex picture, and he understands you quickly ... If you enter a class that is not eager to say a word (and there are a lot of such classes), start showing pictures, and the class will start speaking, and most importantly, will speak freely...".

The use of visual aids is relevant because in schools, as a rule, there is no necessary set of tables, schemes, reproductions, illustrations. However, the expected effect can be achieved if certain requirements are met for presentation of visual aids:

- recognition of visual aids, which should correspond to the written or oral information;

- dynamics of presentation of visual aids. The time of the demonstration should be optimal, and correspond to the currently studied educational information. It is very important not to overdo the effects;

- image sequence algorithm. Let's recall the lessons where the teacher closed (turned over) prepared visual aids to show them at the right time. It was extremely inconvenient, took 
away time from the teacher, the pace of the lesson was lost. Multimedia tools provide the opportunity for the teacher to present the required image when the time comes. The teacher should think over the sequence of images on the screen in detail to make the training effect as large as possible;

- optimal size of visual aids. And this applies not only to the minimum, but also to the maximum size, which can also have a negative impact on the learning process, and to cause a more rapid fatigue of students. Teacher should remember that the optimal image size on the monitor screen does not in any case correspond to the optimal size of the image of the large screen of the projector;

- the optimal number of displayed images on the screen. Do not be too obsessed with the numbers of slides, photos, etc., which can distract students, do not allow to focus on the main thing.

- $\quad$ printed text. It is necessary to pay attention to the following requirements for the text: structure, volume, format [10].

Text from the screen should act as a unit of communication. It has a subordinate character, which helps the teacher to strengthen the meaning, or is an independent unit of information that the teacher deliberately does not voice. It is quite natural, when on the screen there are definitions of terms, key phrases. Often on the screen we can see a kind of a thesis lesson plan. In this case, the main thing is not to overdo it [8].

It has long been evident that a large amount of text is not easily perceived from the screen. The teacher should strive to replace the printed text with visual aids if it is possible. In fact, this is also a text, but presented by another language. It is also important how the printed text will be presented from the screen. As well as visual aids, the text should appear in a time prearranged by the teacher. The teacher either comments on the presented text, or strengthens the oral presented information. It is very important that the teacher does not duplicate the text from the screen. Then the students will not have the illusion of a superfluous element of incoming information. Although there may be cases when the duplication of printed text by a teacher or a student can be didactically justified. Such a technique is used in primary school, when the teacher achieves a comprehensive approach, connecting various channels of perception. Duplication of printed text is also mandatory at any age when conducting multimedia didactic games. In this way the teacher achieves equal conditions for all students: those who can perceive oral information easier, and those who assimilate easier the information of the printed text.

Color, color scheme - when preparing a multimedia lesson, the developer should have at least basic ideas that can successfully affect the design of the color script of the educational episode. Do not neglect the recommendations of psychologists, designers about the influence of color on students' cognitive activity, on the combination of colors, the optimal number of colors on the screen, etc. One should also pay attention to the fact that the color perception on the screen and on the big screen is significantly different, and the multimedia lesson needs to be prepared first of all with the calculation on the screen of the projector.
Sound can play the role of noise effect, sound illustration, soundtrack [9].

As a noise effect, sound can be used to attract students' attention, switching to another type of learning activity. The presence of a multimedia collection of sound effects does not necessarily mean their application. The noise effect should be didactically justified. For example, in the case of a multimedia didactic game, a intermittent sound may be a signal to start a discussion of the question, or, conversely, a signal to end the discussion and answer the question. It is very important that the students get accustomed to this, so that the sound does not cause excessive excitement.

An important role plays sound illustration, as an additional channel of information. For example, a visual representation of animals or birds can be accompanied by their growling, singing, etc. A drawing or photograph of a historical figure may be accompanied by his recorded speech.

Finally, the sound can play the role of an educational soundtrack of a visual image, animation, video. In this case, the teacher should think carefully how rational it will be to use sound in the classroom. What will be the role of the teacher in the course of the soundtrack? It will be more acceptable to use sound as a teaching text in the course of self-preparation for the lesson. In the lesson, you should reduce the use of soundtrack to a minimum [12].

Modern technologies, as is known, allow to use fragments of video films in a multimedia lesson successfully. Using video information and animation can greatly enhance the learning effect. It is the film, or more precisely the small training fragment, that contributes the most to the visualization of the educational process, the presentation of animation results, the simulation of various processes in real-time learning. Where a stationary illustration or a table does not help in teaching, a multidimensional mobile figure, animation, video, and etc. can be of great use. However, when using video information, you should not forget about saving the pace of the lesson. The video should be extremely short in time, and the teacher should take care of providing feedback to the students. That is, video information should be accompanied by a number of developmental questions, stimulating children to communicate, comment on what is happening. In no case should not be allowed to turn the students into passive contemplatives. It is necessary to replace the sound of the video fragment with the live speech of the teacher and students [11].

\section{CONCLUSION}

From all of the above, it can be said that the application of interactive technology at the Life Safety lesson is considered as: a source of additional information on the subject; a way to increase enthusiasm for the subject; the method of selforganization of educational work and self-education, the feasibility of implementing a person-centered approach for the teacher; a way to strengthen the zone of individual initiative and socialization of a man.

Thus, the profession of a teacher is one of those where selfdevelopment, self-improvement are required daily. The activity of the teacher presupposes the necessity for continuous 
education, the process of constant improvement of their professional competence.

\section{REFERENCES}

[1] Ahkiyamova G.R. Features of the use of information technology in lessons "Fundamentals of Life Safety" / G.R. Ahkiyamova // In the world of scientific discoveries. Krasnoyarsk: Scientific and Innovation Center, 2014. № 11.2 (59) P. 899-903.

[2] Ahkiyamova G.R., Khasanova A.R. Transformation of the educational process on the discipline "Fundamentals of life safety" in the context of changes in the fundamental requirements of Life Safety / G.R. Ahkiyamova, A.R. Khasanova // Modern research of social problems (electronic journal). Krasnoyarsk: Scientific and Innovation Center, 2016. - № 11-2. URL: $\mathrm{http}: / /$ ej.soc-journal.ru/archive/11-22016.pdf

[3] Andreeva A. A. The use of multimedia in the education of students on life safety // In the collection: Modern approaches to work with highly motivated high school students Materials V all-Russian scientific and practical conference. 2016. P. 7-11.

[4] Burmakina V.F., Falina I.N. ICT competence of students. - Access mode: http://www.sitos.mesi.ru/Default.aspx?id=6

[5] Gorbunova L.M., Semibratov A.M. Construction of a system for improving the qualifications of teachers in the field of information and communication technologies on the basis of the principle of distribution. Conference of ITO2004. - Access mode: http://ito.edu.ru/2004/Moscow/Late/Late-0-4937.html

[6] Goryunova M.A. Distributed model of professional development of teachers in the field of information and communication technologies: Author's abstract. diss.: Candidate of Sciences. - St. Petersburg, 2006. - P. 22

[7] Henner E.K., Shestakov A.P. Information and communication competence of the teacher: structure, requirements and measurement system // Informatics and education. 2004. № 12. P. 5 - 9.

Jankovic I. A., Kirpichenko E. V., Kvitsiani D. I., Blinov A. V. The use of interactive technologies in the lessons Basics of Life Safety // In the collection: Modern society, education and science collection of scientific papers on the materials of the International scientific-practical conference: in 16 parts. 2015. P. $162-163$

[8] Kuznetsova N.M. Effective interactive educational technology: Regional education: modern trends. 2013. № 2 (20). P. 96-98.

[9] Kuznetsova N. V., Karpacheva T. V. Active and interactive technologies in training of students in the discipline "Theory and methods of life safety training" // In the collection: school of the XXI century: trends and prospects Collection of materials II International scientific and practical conference. Federal state budgetary educational institution of higher professional education "Chuvash state University named I. N. Ulyanov"; "Kharkiv state pedagogical University named after G. S. Skovoroda"; "Aktyubinsk regional state University named after K. Zhubanov"; Centre for scientific cooperation "Interactive plus". 2014. P. $19-22$.

[10] Mueva A. V. Interactive methods of teaching in the professional activity of the teacher Life Safety // In journal: Scientific and practical support for the integration of modern learning environment: problems and prospects, proceedings of the international scientific-practical. 2016. P. 403-410.

[11] Panina TS, Dochkin SA, Kletsov Yu.V. Levels of information and communication competence of pedagogical workers // [Electronic resource]. Access mode: http://www.belpc.ru/krirpo/index.php [12] Popryaduhina E. V. Modern technologies at lessons Basics of Life Safety // In the collection: Actual problems of professional and technical education Collection of scientific articles of the all-Russian scientific-practical conference. Responsible editor N. Ah. Costin. 2015. P. 57-62. 
